\title{
A Comparative Study on the Oxidation of Label-Free Silver Triangular Nanoplates by Peroxides: Main Effects and Sensing Applications
}

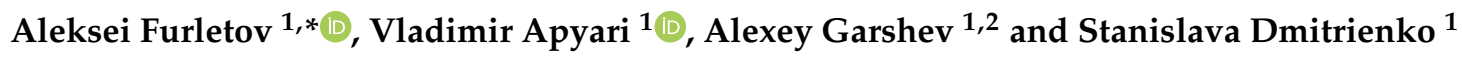 \\ 1 Department of Chemistry, Lomonosov Moscow State University, Leninskie Gory, 119991 Moscow, Russia; \\ apyari@mail.ru (V.A.); alexey.garshev@gmail.com (A.G.); dmitrienko@analyt.chem.msu.ru (S.D.) \\ 2 Department of Materials Science, Lomonosov Moscow State University, Leninskie Gory, \\ 119991 Moscow, Russia \\ * Correspondence: aleksei_furletov@mail.ru
}

Received: 30 July 2020; Accepted: 25 August 2020; Published: 27 August 2020

\begin{abstract}
Nowadays, analytical systems based on silver triangular nanoplates (AgTNPs) have been shown as good prospects for chemical sensing. However, they still remain relatively poorly studied as colorimetric probes for sensing various classes of compounds. This study shows that these nanoparticles are capable of being oxidized by peroxides, including both hydrogen peroxide and its organic derivatives. The oxidation was found to result in a decrease in the AgTNPs' local surface plasmon resonance band intensity at $620 \mathrm{~nm}$. This was proposed for peroxide-sensitive spectrophotometric determination. Five peroxides differing in their structure and number of functional groups were tested. Three of them easily oxidized AgTNPs. The effects of a structure of analytes and main exterior factors on the oxidation are discussed. The detection limits of peroxides in the selected conditions increased in the series peracetic acid $<$ hydrogen peroxide $<$ tert-butyl hydroperoxide, coming to $0.08,1.6$ and $24 \mu \mathrm{mol} \mathrm{L}^{-1}$, respectively. tert-Butyl peroxybenzoate and di-tert-butyl peroxide were found to have no effect on the spectral characteristics of AgTNPs. By the example of hydrogen peroxide, it was found that the determination does not interfere with 100-4000-fold quantities of common inorganic ions. The proposed approach was successfully applied to the analysis of drugs, cosmetics and model mixtures.
\end{abstract}

Keywords: hydrogen peroxide; label-free detection; local surface plasmon resonance; nanoparticles; organic peroxides; silver triangular nanoplates; spectrophotometry

\section{Introduction}

It is well known that hydrogen peroxide and the associated active forms of oxygen (anion radicals, hydroxyl radicals, etc.) play an important role in biochemistry, medicine and environmental monitoring [1-4]. Their excess relative to normal values may indicate the presence of an inflammatory process in the human body, deactivation of mitochondrial biochemical cycles and other important problems [5,6].

To date, many analytical approaches to the qualitative and quantitative determination of hydrogen peroxide have been developed. The attention of most researchers is mainly focused on the enzymatic methods, which have both good sensitivity and good selectivity $[7,8]$. Along with the undoubted advantages, the methods of this group have a significant drawback associated with the instability of enzymes. Being substances of a protein nature, they are extremely sensitive to environmental parameters, such as temperature, $\mathrm{pH}$ and ionic strength, which requires the strictly controlled conditions and greatly complicates the procedure of analysis. In addition, to the best of our knowledge, 
the above-mentioned approach is limited only to hydrogen peroxide and is not applicable to the determination of organic peroxides. Thus, the development of simple, highly sensitive, cheap and express methods for the determination of peroxides as well as the search for correlations between the structure of analytes and their detectability are important tasks.

Noble metal nanoparticles, in particular silver nanoparticles, are widely proposed in chemical analysis for the determination of both organic and inorganic compounds with various functional groups using spectral and colorimetric methods [9-14]. The vast majority of studies considered the problems of the synthesis and application of various analytical systems based on isotropic silver nanoparticles [15-24]. Fewer articles were connected with discussing the applications of anisotropic silver nanoparticles, in particular, silver triangular nanoplates (AgTNPs) and different composite materials based on them [25-33].

Unusual optical properties of silver triangular nanoplates can be explained by the local surface plasmon resonance (LSPR). Relatively large extinction values of silver triangular nanoplates dispersed in an aqueous solution, as well as the possibility of significantly changing their optical properties in the presence of peroxides, allow for considering analytical systems based on AgTNPs as a versatile tool for the detection of hydrogen peroxide [34,35], devoid of many disadvantages of enzymes.

In the present study, the oxidation of label-free AgTNPs by hydrogen peroxide and its organic derivatives was assessed to outline possibilities of this nanoreagent as a colorimetric probe for sensing peroxides.

\section{Materials and Methods}

\subsection{Reagents and Instruments}

In the present study, we used the following reagents: acetic acid (IREA 2000, pure grade), sodium citrate (Sigma-Aldrich, St. Louis, Missouri, USA, $\geq 99.5 \%$ ), tert-butyl peroxybenzoate (TBPB) (Sigma-Aldrich, 98\%), sodium hydroxide (Reachim, pure grade), sodium borohydride (Acros Organics, Belgium, Germany, 99\%), tert-butyl hydroperoxide (TBHP) (Sigma-Aldrich, 70 wt. $\%$ in $\mathrm{H}_{2} \mathrm{O}, 99 \%$ ), poly(N-vinyl-2-pyrrolidone) (Acros Organics, M.W. 58,000 $\mathrm{g} \mathrm{mol}^{-1}, 99 \%$ ), di-tert-butyl peroxide (DTBP) (Sigma-Aldrich, 98\%), hydrogen peroxide (HP) (Sigma-Aldrich, $30 \mathrm{wt} . \%$ in $\mathrm{H}_{2} \mathrm{O}$, ACS), peracetic acid (PAA) (Sigma-Aldrich, $39 \mathrm{wt} . \%$ in glacial acetic acid, pure grade) and silver nitrate (PZTsM-Vtormet, analytical grade). In all experiments, the Millipore Simplicity water purification system was used to obtain deionized water (Merck Millipore, Burlington, MA, USA).

Absorption spectra of AgTNPs in a wavelength range of 400-1100 nm were recorded using an SF-104 spectrophotometer (Aquilon, Nakhodka, Russia). Stirring of solutions was carried out using an Ekros PE-6100 magnetic mixer (Ekros, Novocherkassk, Russia). pH values were measured using an Ekspert 001 pH-meter (Ekoniks Ekspert, Moscow, Russia).

Transmission electron microscope (TEM) images of silver triangular nanoplates were recorded with the Libra 200 microscope (Carl Zeiss, Oberkochen, Germany) using the following technique. Samples of the studied nanoparticles were deposited onto a copper grid support which had been previously coated with a formvar film covered with amorphous carbon. These samples were further dried in air for 20-30 min and then in vacuum using the Turbo Pumping Station Model 655 system (Gatan, Pleasanton, CA, USA) for 10-12 h. All measurements of electrokinetic potentials of the colloidal systems based on silver triangular nanoplates were performed with the Zetasizer Nano ZS light scattering system (Malvern Instruments, Malvern, UK).

\subsection{Synthesis of Silver Triangular Nanoplates in Aqueous Solution}

Synthesis of label-free silver triangular nanoplates was performed according to the method described earlier in the literature [36]. First of all, $2.30 \mathrm{~mL}$ of sodium citrate solution (1\%), $0.60 \mathrm{~mL}$ of poly(N-vinyl-2-pyrrolidone) solution $\left(20 \mathrm{mg} \mathrm{mL}^{-1}\right)$ and $1.20 \mathrm{~mL}$ of hydrogen peroxide solution ( $3 \%$ ) were successively added to $4.80 \mathrm{~mL}$ of $\mathrm{AgNO}_{3}$ solution $(1 \mathrm{mM})$ under vigorous stirring. Then, $1.00 \mathrm{~mL}$ 
of $\mathrm{NaBH}_{4}$ solution $(0.035 \mathrm{M})$ was added into that mixture. After half an hour, when the solution changed its color from yellow to blue, the stirring was stopped. The concentration of silver triangular nanoplates in the resulting colloidal solution was found to be equal to $0.52 \mathrm{mM}$ in terms of atomic silver. A TEM image of AgTNPs is shown in Figure 1a.

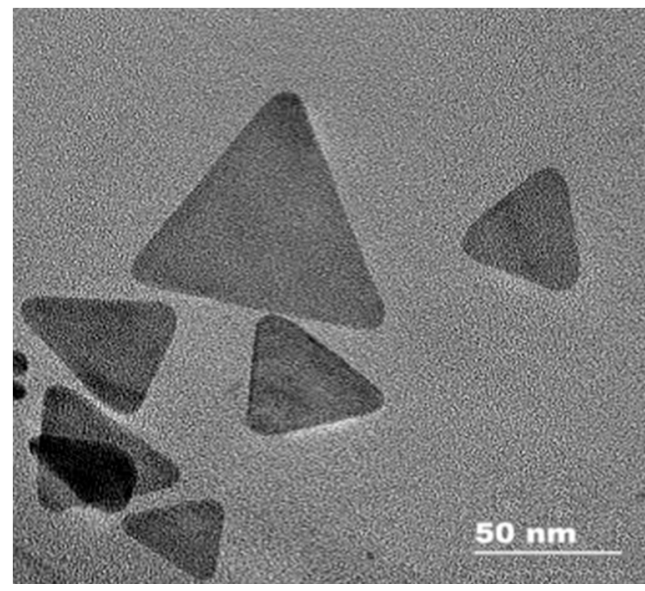

(a)

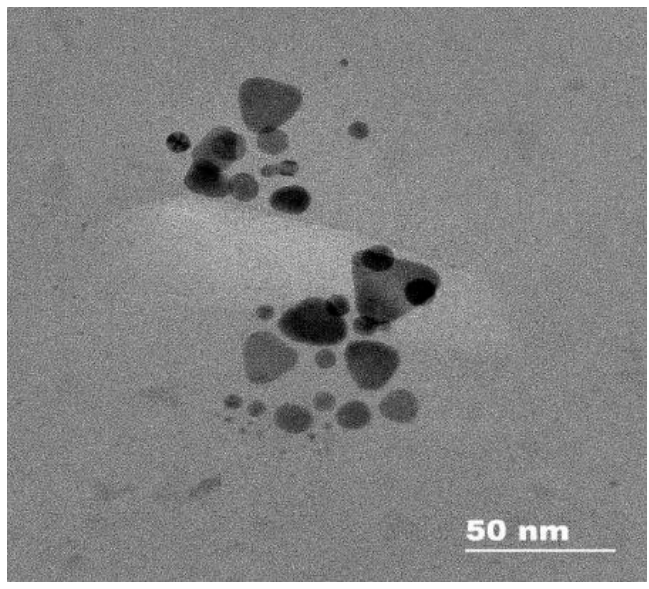

(b)

Figure 1. A TEM image of silver triangular nanoplates (AgTNPs) before (a) and after (b) the interaction with hydrogen peroxide. $c$ (AgTNPs) $=0.16 \mathrm{mM} \mathrm{Ag}, c(\mathrm{HP})=30 \mu \mathrm{M}, \mathrm{pH}$.

\subsection{Procedures}

To plot the kinetic curves of the interaction between AgTNPs and the studied peroxides, certain amounts of peroxides were added into test tubes. After that, $1.50 \mathrm{~mL}$ of AgTNPs solution $(0.52 \mathrm{mM})$ was added into each test tube as well. The final volume of each reaction mixture was adjusted up to $5.00 \mathrm{~mL}$ using the acetate buffer solution $(\mathrm{pH}$ 6.0) as it was found not to adversely affect optical properties of AgTNPs and not to interfere with the determination of peroxides. Absorption spectra of AgTNPs were recorded 1, 5, 10, 15, 20 and 25 min after the last reagent was added.

The effect of $\mathrm{pH}$ on the analytical response was evaluated by the following procedure. First of all, a certain amount of the determined compound was introduced into the test tubes. After that, $1.5 \mathrm{~mL}$ of $0.52 \mathrm{mM}$ AgTNPs solution was added. The final volume was adjusted up to $5.0 \mathrm{~mL}$ with $0.1 \mathrm{M}$ acetic acid and $0.1 \mathrm{M}$ sodium hydroxide solutions mixed with each other in various ratios. After a certain time required to achieve the maximum analytical response, absorption spectra were recorded.

To plot the calibration curves, $1.50 \mathrm{~mL}$ of AgTNPs solution $(0.52 \mathrm{mM})$ and different amounts of peroxides were added into test tubes. The final volume of each reaction mixture was adjusted up to $5.00 \mathrm{~mL}$ using the acetate buffer solution ( $\mathrm{pH}$ 6.0). Absorption spectra of AgTNPs were recorded after $5 \mathrm{~min}$ in the case of HP, $15 \mathrm{~min}$ in the case of PAA, and $20 \mathrm{~min}$ in the case of TBHP.

\section{Results and Discussion}

\subsection{Interaction of Peroxides with Label-Free Silver Triangular Nanoplates}

Interaction of peroxides with AgTNPs as well as with other nanophases is a quite complex process. It may include adsorption onto the nanoparticles, electrostatic interactions, and redox reactions with both peroxides and the reactive oxygen species produced from them. In addition, the above-mentioned interaction is also able to change the state of AgTNPs in solution and, therefore, can affect both LSPR and SERS effects on the surface of nanoparticles [37]. In this sense, oxidation activity and structure of a peroxide may drastically affect its ability to interact with AgTNPs. As a result, analytical features of merit may significantly vary for different peroxides. In this study, five peroxides differing in their oxidation activity and structure of the substituents were studied. Apart from hydrogen peroxide, 
two hydroperoxides (TBHP, PAA) and two fully substituted peroxides (DTBP, TBPB) were chosen (Table 1).

Table 1. Peroxides studied in this work.

\begin{tabular}{|c|c|c|c|}
\hline Chemical Name & $\mathrm{MW}, \mathrm{g} \mathrm{mol}^{-1}$ & Structure & Type $^{a}$ \\
\hline Hydrogen peroxide (HP) & 34.01 & & Unsubstituted \\
\hline $\begin{array}{c}\text { tert-Butyl } \\
\text { hydroperoxide (TBHP) }\end{array}$ & 90.12 & & Monosubstituted, EDS \\
\hline Peracetic acid (PAA) & 76.05 & & Monosubstituted, EAS \\
\hline $\begin{array}{c}\text { di-tert-Butyl } \\
\text { peroxide (DTBP) }\end{array}$ & 146.23 & & Disubstituted, EDS/EDS \\
\hline $\begin{array}{c}\text { tert-Butyl } \\
\text { peroxybenzoate (TBPB) }\end{array}$ & 194.23 & & Disubstituted, EDS/EAS \\
\hline
\end{tabular}

${ }^{\text {a }}$ EDS-electron-donor substituent, EAS-electron-acceptor substituent.

Some important features of AgTNPs oxidation by these peroxides were evaluated. It was found that the interaction of AgTNPs with HP and PAA leads to a remarkable decrease in the LSPR band intensity at $620 \mathrm{~nm}$ (Figure 2), which is especially noticeable in the case of PAA. In all experiments, we considered the value of change in the absorbance of silver triangular nanoplates solutions at their absorption band maximum $(\Delta \mathrm{A})$ as the analytical signal.

TEM images of nanoparticles after their interaction with HP (Figure 1b) show a very small number of silver nanospheres and nanodisks as well as triangular nanoplates with rounded edges. All particles have a size lower than the initial AgTNPs, which is probably a result of their partial oxidation and dissolution. In the case of TBHP containing a bulky electron-donor tert-butyl radical, the changes are manifested to a much lesser extent. The di-substituted peroxides, TBPB and DTBP, do not affect AgTNPs, regardless of the electron-acceptor properties of the substituents (Figure 3). These facts indicate that the oxidation of AgTNPs is promoted by a decrease in the size of substituents in a peroxide molecule and an increase in their electron-acceptor properties determined by the values of inductive 
and mesomeric effects of functional groups of the above-mentioned peroxides. It should be also highlighted that the observed consistent pattern is in good agreement with the values of the oxidation potential of the above peroxides. Indeed, a decrease in the size of substituents in a peroxide molecule, as well as an increase in their electron-acceptor properties, leads to an increase in the oxidation potential of peroxides, which contributes to the easier oxidation of nanoparticles.

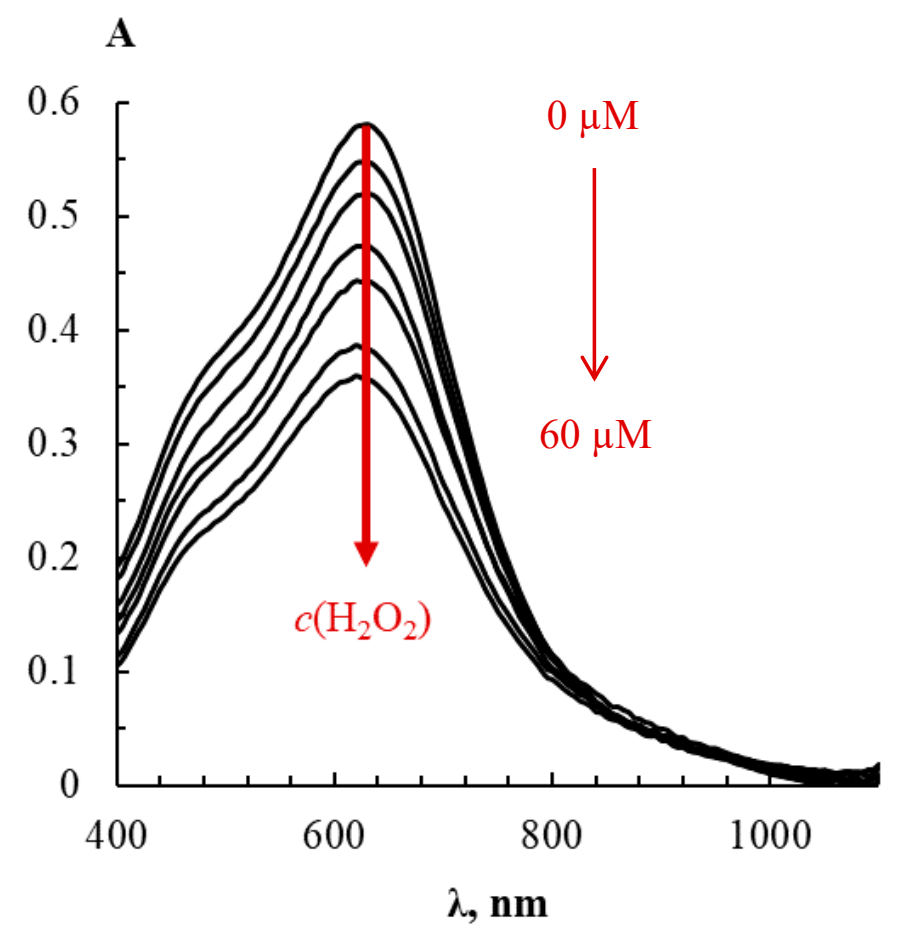

Figure 2. Absorption spectra of AgTNPs colloidal solutions at various concentrations of hydrogen peroxide. $c(\mathrm{AgTNPs})=0.08 \mathrm{mM} \mathrm{Ag}, c(\mathrm{HP})=0-60 \mu \mathrm{M}, \mathrm{pH} 6, t=10 \mathrm{~min}$.

$\Delta \mathbf{A}$

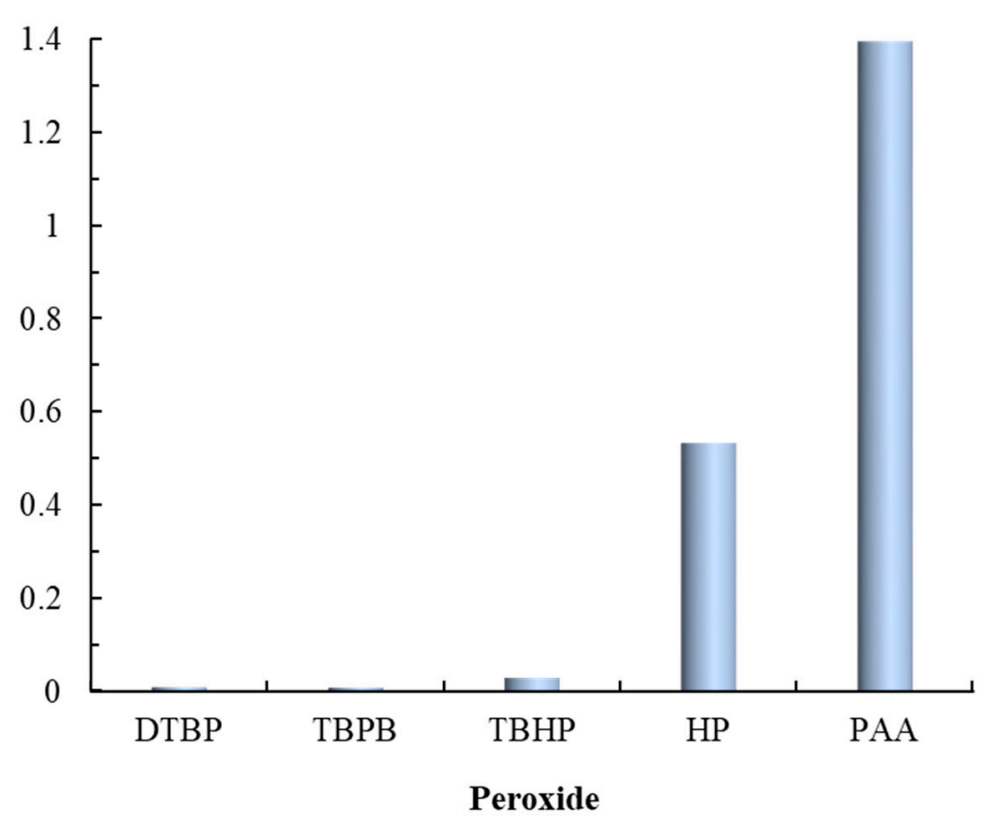

Figure 3. Change in the absorbance of AgTNPs solutions depending on the nature of a peroxide. $c($ AgTNPs $)=0.16 \mathrm{mM} \mathrm{Ag}, c($ peroxide $)=0.1 \mathrm{mM}, \mathrm{pH} 6, t=10 \mathrm{~min}$. 
The observed spectral changes can be considered as the basis of novel spectrophotometric methods for the determination of peroxides. Therefore, the effects of exterior factors such as $\mathrm{pH}$, time, and concentration of AgTNPs should be considered to achieve the best analytical performance of the peroxides determination.

\subsubsection{Effect of $\mathrm{pH}$}

The dependence of AgTNPs absorbance on $\mathrm{pH}$ in the presence of HP, TBHP and PAA was evaluated. The results are represented in Figure 4. It was found that the maximum analytical response is observed in the $\mathrm{pH}$ range of 5-7 in the case of both HP and TBHP, and 5-6 in the case of PAA. A decrease in the change of AgTNPs absorbance with increasing $\mathrm{pH}$ value is probably associated with a decrease in the oxidation potential of peroxides in alkaline medium, which is most clearly observed for PAA due to its electrolytic dissociation, as well as with a decrease in the activity of the nanoparticles themselves. A decrease in the signal at $\mathrm{pH}<5$ is observed regardless of the nature of a peroxide, since it is associated with the instability of AgTNPs under these conditions [38].

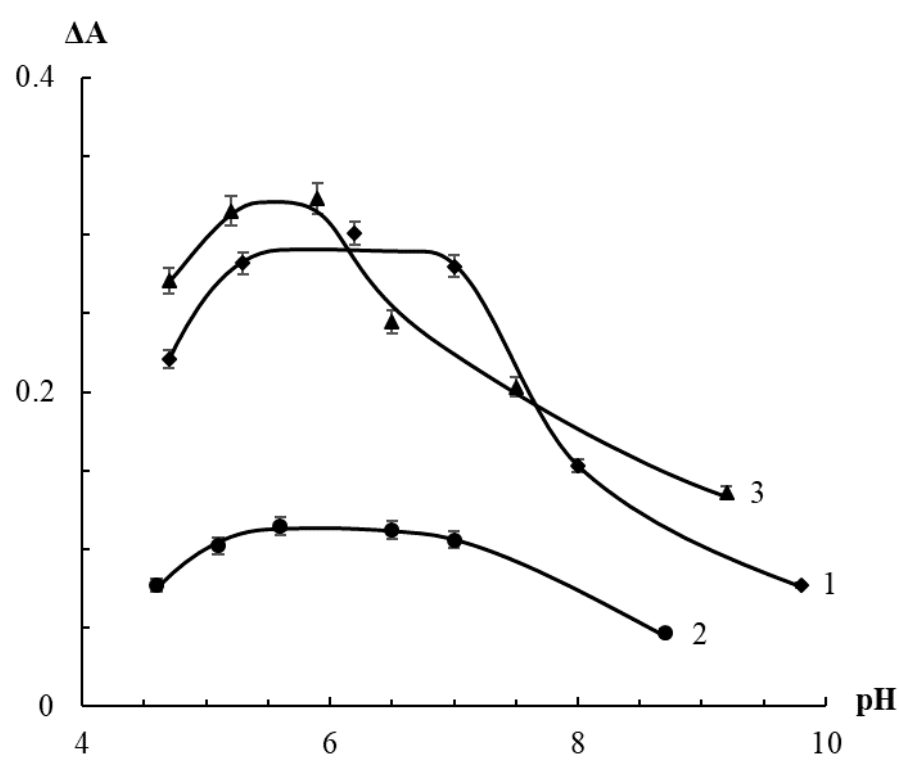

Figure 4. Change in the absorbance of AgTNPs solutions in the presence of hydrogen peroxide (1), tert-butyl hydroperoxide (2) and peracetic acid (3) depending on $\mathrm{pH}$. $c$ (AgTNPs) $=0.16 \mathrm{mM} \mathrm{Ag}$; (1) $c$ $(\mathrm{HP})=50 \mu \mathrm{M}, t=10 \mathrm{~min}$; (2) $c(\mathrm{TBHP})=300 \mu \mathrm{M}, t=20 \mathrm{~min}$; (3) $c(\mathrm{PAA})=3 \mu \mathrm{M}, t=15 \mathrm{~min}$.

\subsubsection{Effect of the Interaction Time}

The influence of the interaction time on sensitivity of the peroxides determination was studied. It was found that the maximum intensity change of the solutions can be observed in 5 min after mixing the reagents in the case of HP, $15 \mathrm{~min}$ in the case of PAA, and $20 \mathrm{~min}$ in the case of TBHP (Figure 5). It is likely that an increase in the size of the radical $\mathrm{R}$ in the molecules of hydroperoxides $\mathrm{ROOH}$ contributes to a decrease in the rate of their interaction with AgTNPs because of the steric effects. 


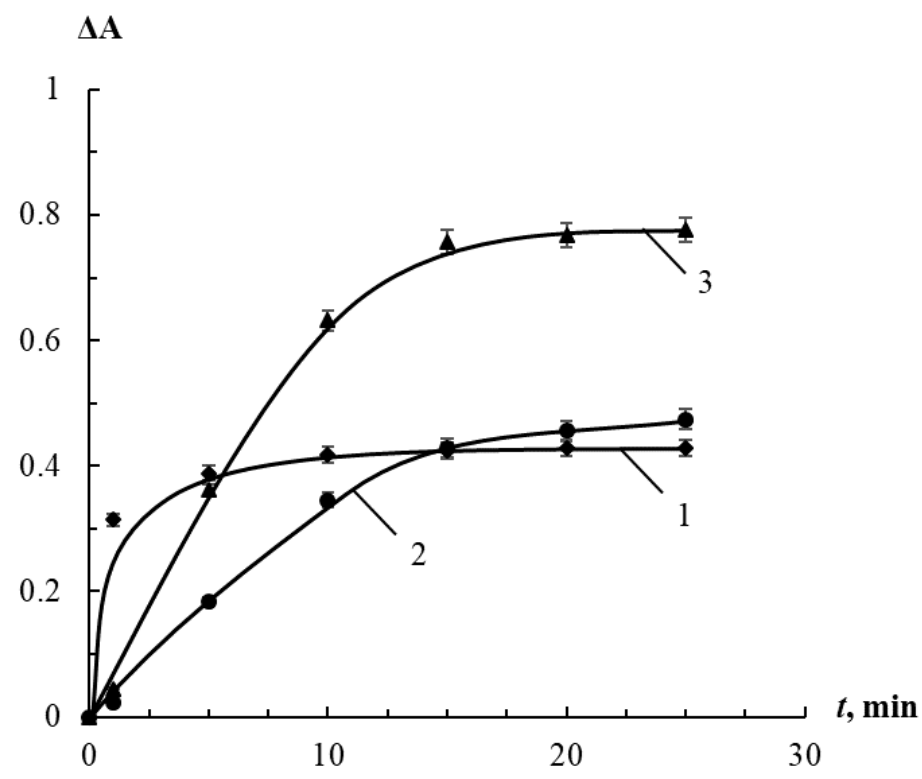

Figure 5. Change in the absorbance of AgTNPs solutions in the presence of hydrogen peroxide (1), tert-butyl hydroperoxide (2) and peracetic acid (3) depending on the interaction time. $c$ (AgTNPs) $=$ $0.16 \mathrm{mM} \mathrm{Ag}, \mathrm{pH}$ 6. (1) $c(\mathrm{HP})=70 \mu \mathrm{M} ;(2) c(\mathrm{TBHP})=1200 \mu \mathrm{M} ;(3) c(\mathrm{PAA})=7.5 \mu \mathrm{M}$.

\subsubsection{Effect of AgTNPs Concentration}

The effect of AgTNPs concentration on the analytical response was evaluated as well. It was found that with an increase in AgTNPs concentration from 0 up to $0.32 \mathrm{mM} \mathrm{Ag}$, sensitivity of the determination of peroxides increases (Figure 6). It should be stressed, however, that measurement errors of the analytical response increase sympathetically. For further experiments, a AgTNPs concentration of $0.16 \mathrm{mM}$ Ag was chosen, which corresponds to the middle of the above-mentioned concentration range.

\section{$\Delta \mathbf{A}$}

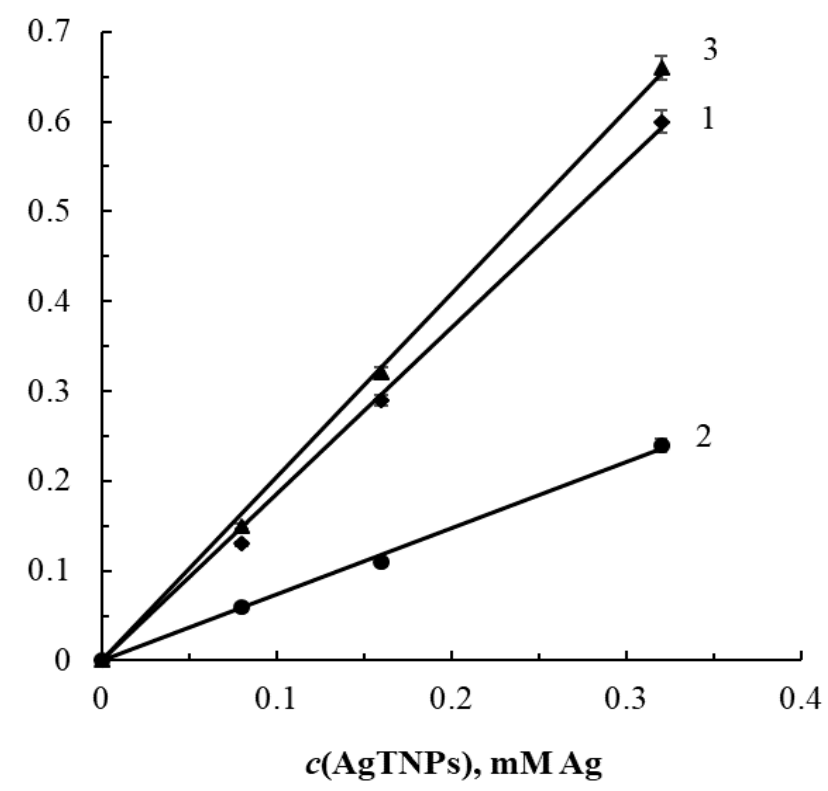

Figure 6. Change in the absorbance of AgTNPs solutions in the presence of $50 \mu \mathrm{M}$ hydrogen peroxide (1), $300 \mu \mathrm{M}$ tert-butyl hydroperoxide (2) and $3 \mu \mathrm{M}$ peracetic acid (3) depending on the AgTNPs concentration. $\mathrm{pH} 6, \mathrm{t}=20 \mathrm{~min}$. 


\subsection{Spectrophotometric Determination of Peroxides}

\subsubsection{Analytical Performance}

All found relations and effects should be taken into account when assessing possibilities of AgTNPs application for spectrophotometric determination of hydrogen peroxide and its organic derivatives. In this study, we have estimated the main analytical features of such an approach. Limits of detection (LODs) and limits of quantitation (LOQs) were evaluated using $3 \sigma$ and $9 \sigma$ criteria, respectively. Some analytical characteristics of the approach proposed in the present article are shown in Table 2. It was found that the limits of peroxide detection in the selected optimal conditions increase in the series peracetic acid < hydrogen peroxide < tert-butyl hydroperoxide and come to $0.08,1.6$, and $24 \mu \mathrm{mol} \mathrm{L}{ }^{-1}$, respectively. In all cases, the determination ranges were about the order of magnitude. The relative standard deviations (RSDs) calculated for concentrations corresponding to midpoints of the determination ranges do not exceed 3\%. This indicates good reproducibility of the analysis.

Table 2. Analytical features of the peroxides determination.

\begin{tabular}{|c|c|c|c|c|c|c|}
\hline Analyte & $k, \mathrm{~L} \mathrm{mmol}^{-1}$ & $r^{2}$ & LOD, $\mu \mathrm{mol} \mathrm{L}-1$ & $\begin{array}{c}\text { Determination } \\
\text { Range, } \mu \text { mol L }{ }^{-1}\end{array}$ & $\mathrm{RSD}^{\mathrm{a}}, \%$ & $\operatorname{RSD}^{b}, \%$ \\
\hline PAA & 106 & 0.990 & 0.08 & $0.25-6$ & 3 & 11.3 \\
\hline $\mathrm{HP}$ & 5.70 & 0.991 & 1.6 & $5-60$ & 2 & 10.5 \\
\hline TBHP & 0.376 & 0.990 & 24 & $72-600$ & 3 & 11.1 \\
\hline
\end{tabular}

\subsubsection{Selectivity Studies}

Selectivity of the proposed method was evaluated by the example of HP determination in the presence of a number of cations and anions. It was found that the determination of $30 \mu \mathrm{mol} \mathrm{L}-1 \mathrm{HP}^{-1}$ is not affected at least by 4000 -fold quantities of $\mathrm{Na}^{+}, \mathrm{K}^{+}, \mathrm{CH}_{3} \mathrm{COO}^{-}, 1000$-fold quantities of $\mathrm{Mg}^{2+}$, $\mathrm{Ca}^{2+}, \mathrm{Ba}^{2+}, \mathrm{Al}^{3+}, \mathrm{NO}_{3}{ }^{-}$and 100 -fold quantities of $\mathrm{Pb}^{2+}, \mathrm{Cu}^{2+}$ and $\mathrm{Cl}^{-}$. However, the determination is affected by 50 -fold quantities of $\mathrm{Fe}^{3+}, \mathrm{Ni}^{2+}, \mathrm{Cr}^{3+}$ and 10 -fold quantities of $\mathrm{Br}^{-}$and $\mathrm{I}^{-}$.

\subsubsection{Sample Analysis}

In order to show the applicability of the proposed method to the analysis of samples, the determination of various peroxides using AgTNPs was performed after appropriate dilution of the samples. The following samples were used: "Hydroperit" formulation (Tatkhimpharmpreparaty, Kazan, Russia) and "Estel De Luxe" hair oxygent (Unicosmetik, Saint-Petersburg, Russia) containing $\mathrm{HP}$ as an active component. Model systems based on tert-butanol spiked with TBHP were also analyzed, which simulate contamination of the chemical reagent with the peroxide product of its oxidation. To confirm the accuracy of HP determination, the "Hydroperit" formulation and "Estel De Luxe" hair oxygent were alternatively analyzed by permanganometric titration with visual detection of the equivalence point. The accuracy of TBHP determination in tert-butanol was assessed using the standard addition method. The results are represented in Tables 3 and 4 . One can see that the results of HP determination coincide with the data provided by manufacturers and the results of the alternative method. In the case of TBHP determination, the found peroxide content matches the added amount. This indicates good accuracy of the determination. RSD values do not exceed $8 \%$, which proves good reproducibility of the AgTNPs-based method. 
Table 3. Determination of hydrogen peroxide in samples $(n=3, p=0.95)$.

\begin{tabular}{|c|c|c|c|c|c|c|}
\hline \multirow{3}{*}{ Sample } & \multicolumn{5}{|c|}{ Content of Hydrogen Peroxide, wt.\% } & \multirow{3}{*}{$t$-test Value ${ }^{c}$} \\
\hline & \multirow{2}{*}{$\begin{array}{l}\text { Declared by } \\
\text { Manufacturer }\end{array}$} & \multicolumn{2}{|c|}{ AgTNPs-Based Method } & \multicolumn{2}{|c|}{ Alternative Method } & \\
\hline & & Found & RSD\% & Found & RSD \% & \\
\hline $\begin{array}{l}\text { Hydroperite } \\
\text { formulation }^{\text {a }}\end{array}$ & 36.2 & $36 \pm 4$ & 5 & $36 \pm 2$ & 2 & 0 \\
\hline $\begin{array}{l}\text { Estel De Luxe hair } \\
\text { oxygen b }\end{array}$ & 9.0 & $8.8 \pm 0.9$ & 4 & $9.3 \pm 0.6$ & 2 & 1.98 \\
\hline
\end{tabular}

${ }^{a}$ Composition of the formulation (per one tablet): $542.55 \mathrm{mg}$ of HP, $957.45 \mathrm{mg}$ of urea; ${ }^{\mathrm{b}}$ Composition of the sample: HP, cetearyl alcohol, ceteareth-20, cetrimonium chloride, EDTA, phosphoric acid, sodium stannate; ${ }^{\mathrm{c}}$ Threshold t-test value $(p=0.95, f=4)$ is 2.78 .

Table 4. Determination of tert-butyl hydroperoxide in a model sample $(n=3, p=0.95)$.

\begin{tabular}{|c|c|c|c|}
\hline \multirow{2}{*}{ Sample } & \multicolumn{2}{|c|}{$\begin{array}{l}\text { Content of tert-Butyl } \\
\text { Hydroperoxide, } \mathrm{mg} \mathrm{g}^{-1}\end{array}$} & \multirow{2}{*}{ RSD $\%$} \\
\hline & Added & Found & \\
\hline Model mixture based on tert-butanol spiked with TBHP & $\begin{array}{c}0 \\
1.2\end{array}$ & $\begin{array}{c}0 \\
1.1 \pm 0.2\end{array}$ & - \\
\hline
\end{tabular}

\subsubsection{Comparison with Other Methods for the Determination of Peroxides}

Some analytical features of other reported methods for peroxides determination are represented in Table 5. One can conclude that the approach proposed in the present study has rather good sensitivity as long as our method makes it possible to detect both peracetic acid and hydrogen peroxide, with several times lower limits of detection than many of the reported methods. Unfortunately, we have failed to find any papers on the determination of TBHP, so it seems to be impossible to compare the calculated LOD with published data in this case. The most sensitive reported methods of PAA and HP determination have LODs of about two or three times better than was achieved with AgTNPs. Nonetheless, they have a number of disadvantages mainly associated with the long duration and high cost of a single analysis. Contrary, the technique proposed in the present study utilizes rather simple equipment and requires a short time for a single analysis as well as seeming to be reasonably selective and sensitive.

Table 5. Comparison of AgTNPs-based method with other methods for peroxides determination.

\begin{tabular}{ccccc}
\hline Analyte & Method & LOD, $\boldsymbol{\mu \text { mol L }} \mathbf{- 1}$ & $\begin{array}{c}\text { Determination } \\
\text { Range, } \boldsymbol{\mu \text { mol L }} \mathbf{- 1}^{-1}\end{array}$ & Reference \\
\hline \multirow{3}{*}{ PAA } & Spectrophotometry & 0.6 & $0.6-100$ & {$[39]$} \\
& Fluorimetry & 0.04 & $0.1-20$ & {$[40]$} \\
& Present method & 0.08 & $0.25-6$ & This article \\
& Spectrophotometry & 1000 & $1000-100,000$ & {$[21]$} \\
& Visual colorimetry & 1000 & $1000-10,000$ & {$[41]$} \\
& Spectrophotometry & 80 & $500-15,000$ & {$[3]$} \\
& Spectrophotometry & 18 & $29-150 ; 290-590$ & {$[22]$} \\
& Light diffraction & 8 & $10-670$ & {$[42]$} \\
& Voltammetry & 2 & $5-600$ & {$[43]$} \\
& Sweep voltammetry & 0.5 & $1-300$ & {$[44]$} \\
& Spectrophotometry & 0.00136 & $0.05-1$ & {$[34]$} \\
& Spectrophotometry & 0.00037 & $10-500$ & {$[35]$} \\
& Present method & 1.6 & $5-60$ & This article \\
\hline
\end{tabular}




\section{Conclusions}

As shown in the present article, AgTNPs are a promising colorimetric probe for sensing hydrogen peroxide and its organic derivatives. It has been found that AgTNPs are capable of being oxidized by both hydrogen peroxide and organic hydroperoxides decreasing the LSPR band intensity at $620 \mathrm{~nm}$. Di-substituted peroxides do not affect AgTNPs. It has been suggested that the oxidation is promoted by a decrease in the size of a substituent in hydroperoxide and an increase in its electron-acceptor properties. The interaction proceeds at $\mathrm{pH}$ from 5 to 6-7 in 5-20 min depending on the nature of the peroxide. The detection limits of peroxides in the selected conditions increase in the series peracetic acid $<$ hydrogen peroxide $<$ tert-butyl hydroperoxide and come to $0.08,1.6$ and $24 \mu \mathrm{mol} \mathrm{L} \mathrm{L}^{-1}$, respectively. It was found that the determination of hydrogen peroxide does not interfere with 100-4000-fold quantities of common inorganic ions. The advantages of the AgTNPs-based method include simplicity, rapidity, good analytical performance, availability of the equipment and ease of the test-method's implementation.

Author Contributions: Conceptualization, A.F., V.A. and S.D.; methodology, V.A.; validation, A.F. and A.G.; formal analysis, A.F. and V.A.; investigation, A.F.; resources, A.G.; writing-original draft preparation, A.F.; writing - review and editing, V.A., A.G. and S.D.; visualization, A.F. and V.A.; supervision, V.A. and S.D.; project administration, S.D. All authors have read and agreed to the published version of the manuscript.

Funding: The reported study was funded by RFBR according to the research project No. 20-33-90019.

Acknowledgments: Some studies were performed using instrumentation provided according to the M.V. Lomonosov Moscow State University Program of Development.

Conflicts of Interest: The authors declare no conflict of interest. The funders had no role in the design of the study; in the collection, analyses, or interpretation of data; in the writing of the manuscript, or in the decision to publish the results.

\section{References}

1. Pillay, C.S.; Eagling, B.D.; Driscoll, S.R.; Rohwer, J.M. Quantitative measures for redox signaling. Free. Rad. Biol. Med. 2016, 96, 290-303. [CrossRef]

2. Briehl, M.M. Oxygen in human health from life to death-An approach to teaching redox biology and signaling to graduate and medical students. Redox. Biol. 2015, 5, 124-139. [CrossRef]

3. Olenin, A.Y.; Olenina, E.G. Spectrophotometric nonenzymatic determination of hydrogen peroxide using silver nanoparticles. J. Anal. Chem. 2017, 72, 234-238. [CrossRef]

4. Muráth, S.; Alsharif, N.B.; Sáringer, S.; Katana, B.; Somosi, Z.; Szilagyi, I. Antioxidant materials based on 2D nanostructures: A review on recent progresses. Crystals 2020, 10, 148. [CrossRef]

5. Beloborodova, N.; Bairamov, I.; Olenin, A.; Shubina, V.; Teplova, V.; Fedotcheva, N. Effect of phenolic acids of microbial origin on production of reactive oxygen species in mitochondria and neutrophils. J. Biomed. Sci. 2012, 19, 89-98. [CrossRef]

6. Rhee, S.G. $\mathrm{H}_{2} \mathrm{O}_{2}$, a necessary evil for cell signaling. Science 2006, 312, 1882-1883. [CrossRef]

7. Rhee, S.G.; Chang, T.S.; Jeong, W.; Kang, D. Methods for detection and measurement of hydrogen peroxide inside and outside of cells. Mol. Cells 2010, 29, 539-549. [CrossRef]

8. Guo, H.; Aleyasin, H.; Dickinson, B.C.; Haskew-Layton, R.E.; Ratan, R.R. Recent advances in hydrogen peroxide imaging for biological applications. Cell. Biosci. 2014, 4, 64-74. [CrossRef]

9. Apyari, V.V.; Dmitrienko, S.G.; Gorbunova, M.V.; Furletov, A.A.; Zolotov, Y.A. Gold and silver nanoparticles in optical molecular absorption spectroscopy. J. Anal. Chem. 2019, 74, 21-32. [CrossRef]

10. Cialla, D.; März, A.; Böhme, R.; Theil, F.; Weber, K.; Schmitt, M.; Popp, J. Surface-enhanced Raman spectroscopy (SERS): Progress and trends. Anal. Bioanal. Chem. 2012, 403, 27-54. [CrossRef]

11. Vilela, D.; González, M.C.; Escarpa, A. Sensing colorimetric approaches based on gold and silver nanoparticles aggregation: Chemical creativity behind the assay. A review. Anal. Chim. Acta 2012, 751, 24-43. [CrossRef] [PubMed]

12. Jiang, X.C.; Yu, A.B. Silver nanoplates: A highly sensitive material toward inorganic anions. Langmuir 2008, 24, 4300-4309. [CrossRef] [PubMed] 
13. Rubira, R.J.G.; Camacho, S.A.; Martin, C.S.; Mejía-Salazar, J.R.; Reyes Gómez, F.; da Silva, R.R.; Oliveira Junior, O.N.; Alessio, P.; Constantino, C.J.L. Designing silver nanoparticles for detecting levodopa (3,4-dihydroxyphenylalanine, L-dopa) using surface-enhanced Raman scattering (SERS). Sensors 2020, $20,15$. [CrossRef] [PubMed]

14. Shiva Prasad, K.; Shruthi, G.; Shivamallu, C. Functionalized silver nano-sensor for colorimetric detection of $\mathrm{Hg}^{2+}$ ions: Facile synthesis and docking studies. Sensors 2018, 18, 2698. [CrossRef]

15. Beyene, H.D.; Werkneh, A.A.; Bezabh, H.K.; Ambaye, T.G. Synthesis paradigm and applications of silver nanoparticles (AgNPs), a review. Sustain. Mater. Technol. 2017, 13, 18-23. [CrossRef]

16. Wang, C.; Bi, X.; Wang, M.; Zhao, X.; Lin, Y. Dual-channel online optical detection platform integrated with a visible light absorption approach for continuous and simultaneous in vivo monitoring of ascorbic acid and copper(II) ions in a living rat brain. Anal. Chem. 2019, 91, 16010-16016. [CrossRef]

17. Yan, P.; Ding, Z.; Li, X.; Dong, Y.; Fu, T.; Wu, Y. Colorimetric sensor array based on Wulff-type boronate functionalized AgNPs at various $\mathrm{pH}$ for bacteria identification. Anal. Chem. 2019, 91, 12134-12137. [CrossRef]

18. Cui, L.; Chen, P.; Chen, S.; Yuan, Z.; Yu, C.; Ren, B.; Zhang, K. In situ study of the antibacterial activity and mechanism of action of silver nanoparticles by surface-enhanced Raman spectroscopy. Anal. Chem. 2013, 85, 5436-5443. [CrossRef]

19. Markina, N.E.; Markin, A.V.; Zakharevich, A.M.; Gorin, D.A.; Rusanova, T.Y.; Goryacheva, I.Y. Multifunctional silver nanoparticle-doped silica for solid-phase extraction and surface-enhanced Raman scattering detection. J. Nanopart. Res. 2016, 18, 353-362. [CrossRef]

20. Komova, N.S.; Pavlov, A.M.; Serdobintsev, A.A.; Galushka, V.V.; Rusanova, T.Y. SERS-platforms based on electrospun nanofibers with embedded silver nanoparticles. Proc. SPIE 2019, 11067, 110671A-1-110671A-7. [CrossRef]

21. Teerasong, S.; Sani, M.; Numsawat, P.; Martchoo, R.; Chompoosor, A.; Nacapricha, D. A silver nanoparticle thin film modified glass substrate as a colourimetric sensor for hydrogen peroxide. J. Exp. Nanosci. 2015, 10, 1327-1335. [CrossRef]

22. Teerasong, S.; Sonsa-Ard, T.; Vimolkanjana, C.; Choengchan, N.; Chompoosor, A.; Nacapricha, D. Colorimetric sensor using silver nanoparticles for determination of hydrogen peroxide based on a flow injection system. $J$. Nanoelectron. Optoelectron. 2013, 8, 446-449. [CrossRef]

23. Apyari, V.V.; Terenteva, E.A.; Kolomnikova, A.R.; Garshev, A.V.; Dmitrienko, S.G.; Zolotov, Y.A. Potentialities of differently-stabilized silver nanoparticles for spectrophotometric determination of peroxides. Talanta 2019, 202, 51-58. [CrossRef] [PubMed]

24. Terenteva, E.A.; Apyari, V.V.; Dmitrienko, S.G.; Garshev, A.V.; Volkov, P.A.; Zolotov, Y.A. Determination of pyrophosphate and sulfate using polyhexamethylene guanidine hydrochloride-stabilized silver nanoparticles. Talanta 2018, 180, 346-351. [CrossRef]

25. Shen, J.; Sun, C.; Wu, X. Silver nanoprisms-based Tb(III) fluorescence sensor for highly selective detection of dopamine. Talanta 2017, 165, 369-376. [CrossRef]

26. Apyari, V.V.; Gorbunova, M.O.; Shevchenko, A.V.; Furletov, A.A.; Volkov, P.A.; Garshev, A.V.; Dmitrienko, S.G.; Zolotov, Y.A. Towards highly selective detection using metal nanoparticles: A case of silver triangular nanoplates and chlorine. Talanta 2018, 176, 406-411. [CrossRef]

27. Gorbunova, M.O.; Baulina, A.A.; Kulyaginova, M.S.; Apyari, V.V.; Furletov, A.A.; Volkov, P.A.; Bochenkov, V.E.; Starukhin, A.S.; Dmitrienko, S.G. Dynamic gas extraction of iodine in combination with a silver triangular nanoplate-modified paper strip for colorimetric determination of iodine and of iodine-interacting compounds. Microchim. Acta 2019, 186, 188-197. [CrossRef]

28. Furletov, A.A.; Apyari, V.V.; Garshev, A.V.; Volkov, P.A.; Tolmacheva, V.V.; Dmitrienko, S.G. Sorption of triangular silver nanoplates on polyurethane foam. Russ. J. Phys. Chem. 2018, 92, 357-360. [CrossRef]

29. Feng, H.; Dong, J.; Wu, X.; Yang, F.; Ma, L.; Liu, X.; Liu, Q. Ultra-large local field enhancement effect of isolated thick triangular silver nanoplates on a silicon substrate in the green waveband. Opt. Lett. 2020, 45, 2099-2102. [CrossRef]

30. Chen, L.; Fu, X.; Lu, W.; Chen, L. Highly sensitive and selective colorimetric sensing of $\mathrm{Hg}^{2+}$ based on the morphology transition of silver nanoprisms. ACS Appl. Mater. Interfaces 2013, 5, 284-290. [CrossRef]

31. Xue, B.; Wang, D.; Zuo, J.; Kong, X.; Zhang, Y.; Liu, X.; Tu, L.; Chang, Y.; Li, C.; Wu, F.; et al. Towards high quality triangular silver nanoprisms: Improved synthesis, six-tip based hot spots and ultra-high local surface plasmon resonance sensitivity. Nanoscale 2015, 7, 8048-8057. [CrossRef] [PubMed] 
32. He, Y.; Yu, H. A novel triangular silver nanoprisms-based surface plasmon resonance assay for free chlorine. Analyst 2015, 140, 902-906. [CrossRef] [PubMed]

33. Brandon, M.P.; Ledwith, D.M.; Kelly, J.M. Preparation of saline-stable, silica-coated triangular silver nanoplates of use for optical sensing. J. Colloid. Interface. Sci. 2014, 415, 77-84. [CrossRef] [PubMed]

34. Chen, Z.; Zhang, C.; Wu, Q.; Li, K.; Tan, L. Application of triangular silver nanoplates for colorimetric detection of $\mathrm{H}_{2} \mathrm{O}_{2}$. Sens. Actuat. B Chem. 2015, 220, 314-317. [CrossRef]

35. Zhang, L.; Li, L. Colorimetric detection of hydrogen peroxide using silver nanoparticles with three different morphologies. Anal. Methods 2016, 8, 6691-6695. [CrossRef]

36. Métraux, G.S.; Mirkin, C.A. Rapid thermal synthesis of silver nanoprisms with chemically tailorable thickness. Adv. Mater. 2005, 17, 412-415. [CrossRef]

37. Mitsai, E.; Kuchmizhak, A.; Pustovalov, E.; Sergeev, A.; Mironenko, A.; Bratskaya, S.; Linklater, D.P.; Balcytis, A.; Ivanova, E.; Juodkazis, S. Chemically non-perturbing SERS detection of a catalytic reaction with black silicon. Nanoscale 2018, 10,9780-9787. [CrossRef]

38. Millstone, J.E.; Hurst, S.J.; Metraux, G.S.; Cutler, J.I.; Mirkin, C.A. Colloidal gold and silver triangular nanoprisms. Small 2009, 5, 646-664. [CrossRef]

39. Sanz, V.; de Marcos, S.; Galbán, J. Hydrogen peroxide and peracetic acid determination in waste water using a reversible reagentless biosensor. Anal. Chim. Acta 2007, 583, 332-339. [CrossRef]

40. Lim, D.S.; Lee, Y.J.; Yoo, J.H.; Choi, M.G.; Paek, K.; Koh, H.R.; Chang, S.-K. Fluorometric analysis of peracetic acid by the oxidative hydroxylation of a phenylboronic acid containing dye. Sens. Actuat. B Chem. 2019, 298, 126824. [CrossRef]

41. Roy, K.; Sarkar, C.K.; Ghosh, C.K. Fast colourimetric detection of $\mathrm{H}_{2} \mathrm{O}_{2}$ by biogenic silver nanoparticles synthesized using Benincasa hispida fruit extract. Nanotechnol. Rev. 2016, 5, 251-258. [CrossRef]

42. Yoshikawa, H.; Hieda, K.; Ikeda, K.; Tamiya, E. Hydrogen peroxide detection with a silver nanoparticle grating chip fabricated by plasmonic plating. Anal. Methods 2019, 11, 2991-2996. [CrossRef]

43. Gatselou, V.A.; Giokas, D.L.; Vlessidis, A.G.; Prodromidis, M.I. Rhodium nanoparticle-modified screen-printed graphite electrodes for the determination of hydrogen peroxide in tea extracts in the presence of oxygen. Talanta 2015, 134, 482-487. [CrossRef] [PubMed]

44. Miao, P.; Wang, B.D.; Yin, J.; Chen, X.F.; Tang, Y.G. Electrochemical tracking hydrogen peroxide secretion in live cells based on autocatalytic oxidation reaction of silver nanoparticles. Electrochem. Commun. 2015, 53, 37-40. [CrossRef]

(C) 2020 by the authors. Licensee MDPI, Basel, Switzerland. This article is an open access article distributed under the terms and conditions of the Creative Commons Attribution (CC BY) license (http://creativecommons.org/licenses/by/4.0/). 